\title{
The influence of ultra-pasteurization by indirect heating versus direct steam injection on skim and $2 \%$ fat milks
}

\author{
A. P. Lee, ${ }^{*}$ D. M. Barbano, $†$ and M. A. Drake*1 \\ *Department of Food, Bioprocessing and Nutrition Sciences, Southeast Dairy Foods Research Center, North Carolina State University, \\ Raleigh 27695 \\ †Department of Food Science, Northeast Dairy Research Center, Cornell University, Ithaca, NY 14850
}

\begin{abstract}
Fluid milk is traditionally pasteurized by high temperature, short time (HTST) pasteurization, which requires heating to at least $72^{\circ} \mathrm{C}$ for $15 \mathrm{~s}$. Ultra-pasteurization (UP) extends milk shelf life and is defined as heating to at least $138^{\circ} \mathrm{C}$ for $2 \mathrm{~s}$. The UP process can be done by indirect heating (IND) or by direct steam injection (DSI). The influence of these 2 UP methods on milk flavor has not been widely investigated. The objective of this study was to compare the effect of HTST, IND-UP, and DSI-UP on sensory perception of fluid milk. Raw skim and standardized $2 \%$ milks were pasteurized at $140^{\circ} \mathrm{C}$ for $2.3 \mathrm{~s}$ by IND or DSI or by $\operatorname{HTST}\left(78^{\circ} \mathrm{C}, 15 \mathrm{~s}\right)$ and homogenized at $20.7 \mathrm{MPa}$. The processed milks were stored in light-shielded opaque high-density polyethylene containers at $4^{\circ} \mathrm{C}$ and examined by descriptive analysis and microbial analysis on $\mathrm{d}$ 3,7 , and 14 . Furosine and serum protein denaturation analyses were performed on d 0 and 14 as an indicator of heat treatment. Last, consumer acceptance testing was conducted at $\mathrm{d} 10$, with adults $(\mathrm{n}=250)$ and children (ages 8 to13 y, $\mathrm{n}=100$ ) who were self-reported consumers of skim or $2 \%$ milk; consumers only received samples for either skim or $2 \%$ milk. The entire experiment was repeated in triplicate. Milks treated by HTST had lower cooked flavor than either UP milk. Milks heated by DSI-UP were characterized by sulfur or eggy and cooked flavors, whereas IND-UP milks had higher sweet aromatic and sweet taste compared with DSI-UP milk. Aromatic flavor intensities of all milks decreased across $14 \mathrm{~d}$ of storage. Furosine concentrations and serum protein denaturation were highest for the IND treatments, followed by DSI and HTST. Furosine content in both skim and $2 \%$ milk increased with time, but the increase was faster in IND-UP skim milk. Adult
\end{abstract}

Received August 21, 2016.

Accepted October 31, 2016.

${ }^{1}$ Corresponding author: mdrake@ncsu.edu and child consumers preferred HTST milk over either UP milk, regardless of fat content. Ultra-pasteurization by IND or DSI did not affect consumer acceptance at $10 \mathrm{~d}$ postprocessing, but traditional HTST milks were preferred by consumers of all ages.

Key words: fluid milk, ultra-pasteurization, direct steam injection, flavor, consumer acceptance

\section{INTRODUCTION}

Extended shelf life milks are a current industry trend to meet supply chain demands in the United States. With per capita fluid milk consumption declining $35 \%$ over the past $40 \mathrm{yr}$ (USDA ERS, 2015), nonconventional processing methods for milk are desirable to compete in the beverage industry. Typical US milks are processed by HTST pasteurization (minimum of $72^{\circ} \mathrm{C}$ for $15 \mathrm{~s}$ ), resulting in shelf lives of 2 to 3 wk due to bacterial spoilage limitations (Boor, 2001). This is compared with soft drinks and juices, which can have a 2- to 9-mo shelf life. Ultra-pasteurization (UP) is one method that can extend the shelf life of milk to periods comparable to soft drinks and juices. However, the extreme thermal treatment of this process can affect the sensory properties of milk, resulting in changes to consumer perception and acceptance of the milk compared with typical HTST milks. Ultra-pasteurization is defined by 21CFR131.3 (FDA, 2015) as thermal processing of milk "at or above $138^{\circ} \mathrm{C}\left(280^{\circ} \mathrm{F}\right)$ for at least two (2) seconds" to produce a product for extended shelf life under refrigeration. The thermal treatment of the UP process destroys not only pathogenic bacteria, but also spoilage microorganisms that are not completely destroyed during conventional HTST pasteurization.

Direct heating systems for UP treatment use superheated steam that is applied directly to the product, either by injecting the steam in-line into the product (direct steam injection) or by allowing product to pass through a steam-filled chamber (steam infusion; Bylund, 2003). The addition of steam to products adds water to the product and necessitates the removal of water by vacuum, which also acts to instantaneously 
cool the product (Datta et al., 2002). Mehta (1980) also previously reported that the cooked flavor of direct heat-treated milks was reduced due to removal of sulfhydryl groups by vacuum cooling. Direct methods also have advantages over indirect heating by tubular or plate heat exchangers in that the direct contact with the heating medium followed by instant cooling by vacuum allows for more efficient heat transfer. This produces smaller areas under the curve in the time-temperature profile of the treated product, limiting product quality loss from excess heat exposure (Datta et al., 2002; Bylund, 2003). Direct heat transfer by steam also greatly limits burn-on and fouling, as no heat transfer surfaces are present for the final heating step (Jelen, 1982).

Heat treatment, both time and temperature, affects milk sensory properties. Previous studies have noted several sensory differences in milks treated by UP methods, including cooked flavor and aroma, caramelized flavor, sweet, bitter, astringency, and color differences. The sulfurous, eggy flavor in some heated milk has been attributed to sulfhydryl compounds released from whey proteins, specifically $\beta-L G$, and proteins in the milk fat globule membrane due to thermal treatment (Mehta, 1980; Calvo and de la Hoz, 1992). Caramelized and other "brown" flavors are attributed to nonenzymatic browning reactions, such as from protein or sugar breakdown or by Maillard reaction (Shipe et al., 1978; Calvo and de la Hoz, 1992). These flavors typically decrease over time (Deane et al., 1967; Shipe et al., 1978); however, flavor differences are still present in milks even after several weeks of storage (Chapman and Boor, 2001; Grabowski et al., 2013). These flavor differences contribute to consumer perception of the milks. Chapman and Boor (2001) reported that children ages 6 to 11 yr old preferred HTST milk $1 \mathrm{~d}$ postprocessing over UHT milk at 24 to $30 \mathrm{~d}$ postprocessing, which were both liked more than UP milk at 6 to $7 \mathrm{~d}$ postprocessing. Gandy et al. (2008) reported consumer preference for HTST milks pasteurized at $79^{\circ} \mathrm{C}$ at $6 \mathrm{~d}$ postprocessing compared with milks pasteurized at $77^{\circ}, 82^{\circ}$, and $85^{\circ} \mathrm{C}$. Consumer clusters were distinguished by liking or disliking of cooked flavor (Gandy et al., 2008). In previous studies, descriptive analysis was not conducted. Studies have not compared consumer perception of UP milks to HTST milks in the past $10 \mathrm{yr}$, despite increased prevalence of UP milks in the marketplace and, presumably, increased consumer exposure to UP milk. Furthermore, and importantly, no published research has directly addressed the sensory properties of UP milks processed by indirect (IND) or direct steam injection (DSI); DSI UP is a more recent technology and is replacing, at least in part, many IND systems due to increased heat transfer efficiency.
Our study was designed to compare the sensory effects of these 2 UP techniques to each other and to traditional HTST milk. The objective of the current study was to understand the effect of heat treatment, UP with either DSI or IND and HTST, on sensory properties and consumer acceptance of skim and $2 \%$ fat milks.

\section{MATERIALS AND METHODS}

\section{Sample Preparation}

Prior to the study, preliminary processing runs were done for each of the 3 thermal processes that had different hardware configurations of the Microthermics milk processing system (Microthermics, Raleigh, NC). The milk going into the processing system and exiting the processing system were tested for fat, protein, and lactose by mid-infrared milk analysis, for freezing point using a milk cryoscope (model 4250, Advanced Instruments Inc., Norwood, MA), and for particle size using a laser light-scattering particle size analyzer. The purpose of the preliminary runs was to determine the volume of product that needed to be processed in each configuration to completely flush out water from the system and to determine if the homogenizer was performing properly. In the case of DSI, the cryoscope measures were also used to determine if the water added by steam injection was removed. The total volume of product need to flush water out of the Microthermics processing system was 10,12 , and $12 \mathrm{~L}$ for HTST, IND-UP, and DSI-UP, respectively.

For this study, $200 \mathrm{~L}$ of raw skim milk (3.1\% protein, $0.07 \%$ fat) and raw cream ( $45.4 \%$ fat) were obtained from the North Carolina State University dairy facility. The cream was separated from raw whole milk by a cold bowl separator (model 590, Separators Inc., Indianapolis, IN). One hundred liters of the raw skim milk was standardized to $2 \%$ fat milk with the raw cream. A Microthermics EHVH pasteurization unit running T12B software (10.11.12.90, v6.0, build 104) with a 2-stage homogenizer (model NS2006H, GEA Niro Soavi, Parma, Italy) was used to process the milks. For the HTST treatment, raw skim and raw $2 \%$ milk were processed at a flow rate of $2.0 \mathrm{~L} / \mathrm{min}$. Backpressure between the inlet pump and the homogenizer was maintained at $420 \mathrm{kPa}$. Following preheating to $60^{\circ} \mathrm{C}$, the milks were homogenized and pasteurized at $78^{\circ} \mathrm{C}$ for $15 \mathrm{~s}$ before cooling to $10^{\circ} \mathrm{C}$ (Figure 1a). The IND-UP milks were processed at $1.3 \mathrm{~L} / \mathrm{min}$ flow rate with the same backpressure applied to the homogenizer as with HTST. The raw milks were preheated to $90^{\circ} \mathrm{C}$ then UP at $140^{\circ} \mathrm{C}$ for $2.3 \mathrm{~s}$ by the indirect heater. The milk was 
cooled to $85^{\circ} \mathrm{C}$ before homogenization and then cooled by a second cooler to $10^{\circ} \mathrm{C}$ before packaging (Figure $1 \mathrm{~b})$. For the DSI-UP milk, raw milks were processed at a flow rate of $1.2 \mathrm{~L} / \mathrm{min}$. The milks were also preheated to $90^{\circ} \mathrm{C}$, then heated to $140^{\circ} \mathrm{C}$ for $2.3 \mathrm{~s}$ under $330 \mathrm{kPa}$ pressure by direct culinary steam injection (model LG30, Electro-Steam Generator Corp., Alexandria, VA) using a Microthermics Steam Injection Module with Cub 5 software (version 3.1), then cooled to $85^{\circ} \mathrm{C}$ by vacuum cooling under a $1,040-\mathrm{mmHg}$ vacuum to remove both heat and added water. Added water removal was checked by measuring milk freezing point before and after the DSI-UP process. The DSI-UP milk was then homogenized and cooled to $10^{\circ} \mathrm{C}$ (Figure 1b). All milks were homogenized at $20.7 \mathrm{MPa}$ total pressure with 3.4 $\mathrm{MPa}$ on the second stage. Hold times were calculated under laminar flow assumptions. Milks were packaged in half-gallon, light-shielded milk jugs (Upstate Niagara Cooperative Inc., Buffalo, NY) and stored at $4^{\circ} \mathrm{C}$. The order of processing was randomized between replicates a)

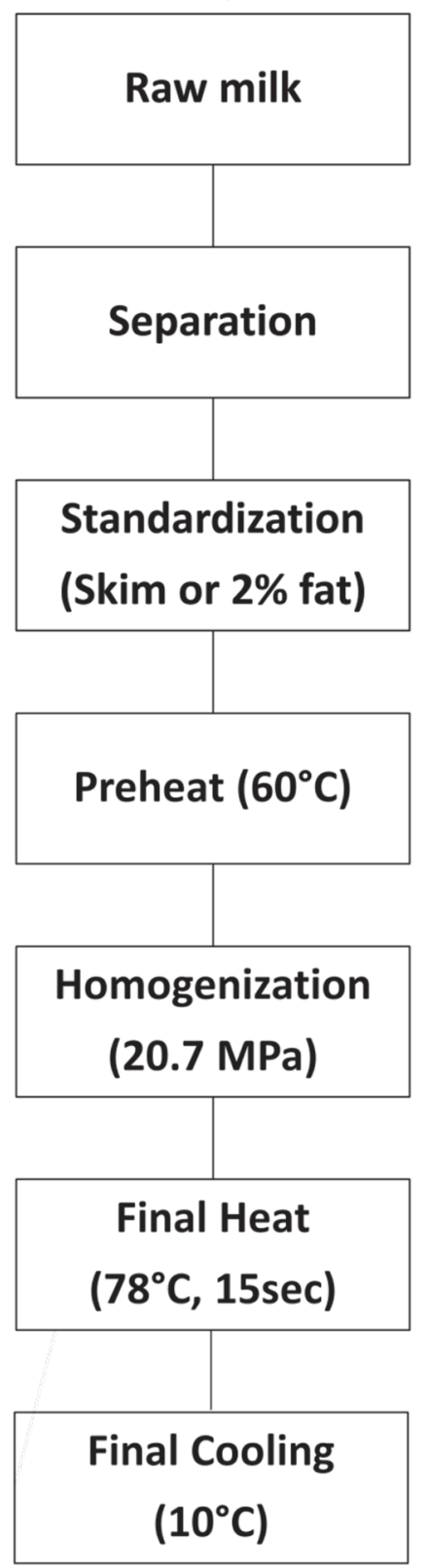

b)

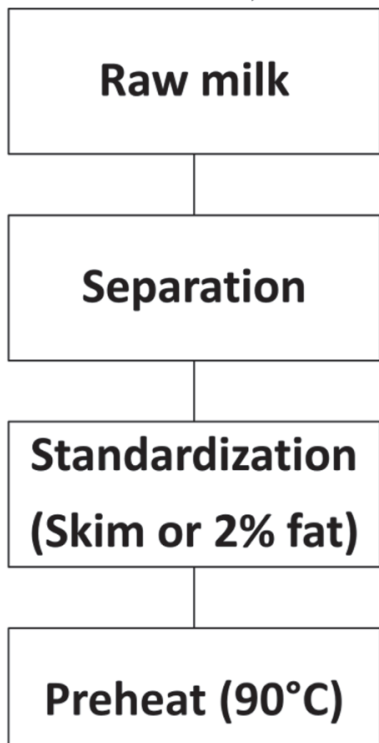

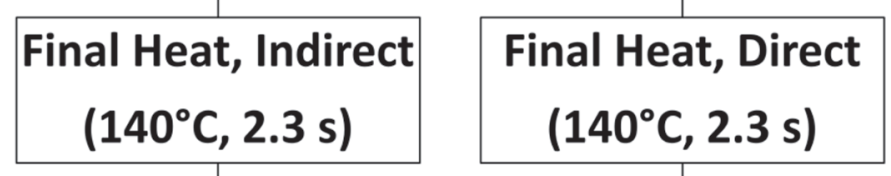

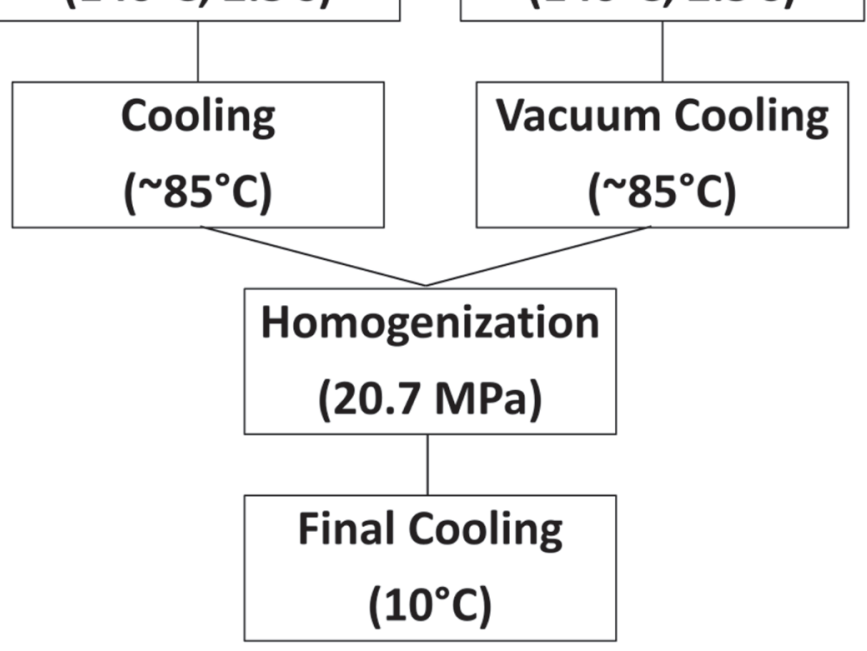

Figure 1. Process flow diagram for (a) HTST and (b) ultra-pasteurization. 
to account for process order effects. The experiment was repeated in triplicate.

\section{Microbiological and Proximate Analysis}

All milks were tested for aerobic plate count (APC; AOAC International, 2012; method 990.12) and coliform count (AOAC International, 2012; method 991.14) using Petrifilm plates (Aerobic Count Plates and Coliform Count Plates, 3M, St. Paul, MN). The $\mathrm{APC}$ and $\mathrm{CC}$ plates were incubated at $32^{\circ} \pm 1^{\circ} \mathrm{C}$ for 24 and $48 \mathrm{~h}$, respectively. Pasteurized milks were tested at 3,7 , and $14 \mathrm{~d}$ after processing. Samples were plated in triplicate. Proximate analyses for fat, protein, and solids were measured by a Fourier-transform mid-infrared milk analyzer (LactoScope FTIR; Delta Instruments BV, Drachten, the Netherlands). Precalibration (Lynch et al., 2006) and calibration (Kaylegian et al., 2006) of the mid-infrared milk analyzer were done as previously described. Total nitrogen (TN), non-casein nitrogen $(\mathbf{N C N}), \mathrm{NPN}$, and true protein content [(TN - NPN) $\times 6.38$ ] were measured by Kjeldahl analysis (AOAC method 991.22; Barbano and Clark, 1990; Barbano and Lynch, 1991; Lynch and Barbano, 1998). Milk pasteurization was confirmed by alkaline phosphatase test (AOAC method 946.03; Phos-Kit, Weber Scientific, Hamilton, NJ). Fat particle size was determined using a Mastersizer 2000 (Malvern Instrument Ltd., Worchestire, UK) as previously described (DiMarzo et al., 2016). Hunter L, a, and b values were measured at d 0 to determine whiteness, greenness to redness, and blueness to yellowness, respectively. Values were generated from the diffuse reflectance in the range of 360 to $750 \mathrm{~nm}$ at $10-\mathrm{nm}$ intervals using illuminant A at $16.5^{\circ} \mathrm{C}$, as described by Quiñones et al. $(1997,1998)$ and Misawa et al. (2016). Milk pH was measured using a solid polymer electrode (HA405-DXK-S8/120, Mettler-Toledo) and an Accumet $915 \mathrm{pH}$ meter (Fisher Scientific, Pittsburgh, PA) that was calibrated at $16.5^{\circ} \mathrm{C}$ using standard $\mathrm{pH} 4$ and 7 buffer solutions (SB101, SB107, Fisher Scientific) with the manufacturer's buffer temperature-correction factors applied.

\section{Serum Protein Denaturation and Furosine Analysis}

Serum protein (SP) denaturation and furosine content of pasteurized milks were used as indicators of thermal treatment. The percentage of SP for raw, HTST, IND-UP, and DSI-UP were calculated as the difference between NCN and NPN content from Kjeldahl analysis of the raw skim or raw $2 \%$ milks. The SP of the raw skim or raw $2 \%$ milk minus the SP content of the thermally treated divided by the raw milk SP times $100 \%$ was the percentage denaturation of the SP due to the thermal process. Furosine analysis was conducted on the pasteurized milks at $\mathrm{d} 0$ and 14 . The analysis was conducted using reversed-phase HPLC analysis according to the method by Resmini et al. (1990) with modifications. Briefly, milks were hydrolyzed by mixing $2 \mathrm{~mL}$ of milk with $6 \mathrm{~mL}$ of $10.6 \mathrm{M} \mathrm{HCl}$, followed by bubbling with nitrogen, then heating at $110^{\circ} \mathrm{C}$ for $23 \mathrm{~h}$. A reversed-phase solid phase extraction microcolumn (Discovery DSC-18, Supelco, Bellefonte, PA) was conditioned with $3 \mathrm{~mL}$ of methanol, followed by $6 \mathrm{~mL}$ of HPLC-grade water, before extracting $0.5 \mathrm{~mL}$ of the milk hydrolysate with $3 \mathrm{~mL}$ of $3 \mathrm{M} \mathrm{HCl}$. Furosine was quantified by reversed-phase HPLC (Breeze HPLC, Waters, Milford, MA) with a $0.4 \%$ acetic acid solution mobile phase filtered through a $0.45-\mu \mathrm{m}$ filter (Nylaflow, Pall Corporation, Port Washington, NY). Fifty microliters of the filtered hydrolysate was injected (Waters 2707 autosampler) onto the column (Luna $5 \mu \mathrm{m}$ C8 100A 250 $\times 4.6 \mathrm{~mm}$, Phenomenex Inc., Torrance, CA) at a flow rate of $1.2 \mathrm{~mL} / \mathrm{min}$ by a binary pump (Waters 1525). A photodiode array detector (Waters 2998) was used to measure the absorbance at $280 \mathrm{~nm}$. The run time for each sample was $10 \mathrm{~min}$. Samples were evaluated in duplicate.

\section{Descriptive Sensory Analysis}

Sensory testing was conducted in accordance with the North Carolina State University Institutional Review Board for the Protection of Human Subjects in Research regulations. A trained sensory panel documented sensory attributes of milk at d 3, 7, and 14. Each panelist ( 4 women, 2 men, ages 21 to $55 \mathrm{yr}$ ) had a minimum of $50 \mathrm{~h}$ of experience evaluating flavor and mouthfeel or texture attributes of foods using the Spectrum method (Meilgaard et al., 2007), and at least $40 \mathrm{~h}$ of previous experience with evaluation of fluid milk sensory properties using an established sensory language (Croissant et al., 2007; McCarthy et al., 2017). Milks (30 mL) were dispensed into lidded 59-mL soufflé cups (Dart Container Corp., Mason, MI) with random 3-digit blinding codes. Samples were prepared with overhead lights off to prevent light oxidation. Milks were tempered to $10^{\circ} \mathrm{C}$ and evaluated using paper ballots. Each panelist evaluated each milk in duplicate.

The trained panel also documented color, opacity, and viscosity attributes in separate sessions (McCarthy et al., 2017). Briefly, $80 \mathrm{~mL}$ of milk was dispensed into $100 \times 10 \mathrm{~mm}$ clear, plastic Petri dishes (Thermo Scientific, Waltham, MA) and placed onto a white paper background. Paint chips were used as references for white and yellow color [Behr "Ultra Pure White" PPU18-06 $=0(\mathrm{~L}=97.68, \mathrm{a}=-0.84, \mathrm{~b}=2.22)$ and "Glass of Milk" P260-1u = 3.5 $(\mathrm{L}=96.21, \mathrm{a}=-0.05$, 
$\mathrm{b}=11.03)$; Behr Process Corp., Santa Ana, CA]. For opacity, milks were dispensed into 118-mL black soufflé cups with random 3 -digit blinding codes. Water was used as a reference of 0 and whole-fat, HTST milk was assigned a 12 for opacity. Viscosity was determined by determining the amount of force needed to slurp 1 teaspoon of milk from a spoon. The references for viscosity were water $=0$ and heavy cream $=3.2$ (Meilgaard et al., 2007).

\section{Consumer Acceptance Testing}

Consumer acceptance testing was conducted in accordance with the North Carolina State University Institutional Review Board for the Protection of Human Subjects in Research regulations. Testing was conducted $10 \mathrm{~d}$ after processing. Self-reported milk consumers were recruited using a survey constructed in SSI Web (version 8.4.8, Orem, UT) launched into a database of $>7,500$ consumers maintained by North Carolina State University. Children (age 8 to 13 yr) were recruited by parental consent. Consumers were recruited based on milk fat content most often consumed for a minimum of 100 adult consumers and 50 child consumers per milk fat treatment. Skim milk drinkers were presented the 3 skim milk treatments and low-fat milk drinkers received the $2 \%$ fat milks. Milks $(88 \mathrm{~mL})$ were served at $10^{\circ} \mathrm{C}$ in $177-\mathrm{mL}$ Styrofoam cups (Dart Container Corp.) with random 3-digit blinding codes. Consumers were presented samples monadically using a Williams design serving order. Adult consumers were asked to evaluate appearance, aroma, overall liking, flavor, freshness, cooked flavor, mouthfeel/thickness/viscosity, and aftertaste on a 9 -point hedonic scale, where 1 was dislike extremely and 9 is like extremely. Just-about-right (JAR) questions were asked for sample flavor, mouthfeel/thickness/viscosity, and aftertaste on a 5-point scale, where 1 was not nearly enough flavor, not nearly thick enough, or much too mild, and 5 was much too much flavor, much too thick, or much too strong, for each question category, respectively. Children received a modified ballot which asked questions in the same categories as the adult ballot. A 7-point, smiley face hedonic scale was used for children where 1 was super bad and 7 was super good. For mouthfeel/thickness/ viscosity, children were asked a JAR question where 1 was too thin, needs to be thicker, 2 was JAR, and 3 was too thick, needs to be thinner ( $\mathrm{Li}$ et al., 2015). A 2-min rest was enforced between milks to allow panelists to cleanse their palate using unsalted crackers and deionized water. A forced-choice preference was asked after all milks were tasted. Panelists were compensated with a $\$ 20$ (adult) or $\$ 30$ (children) gift card. Compusense
Cloud software (ver 7.6, Compusense Inc., Guelph, Canada) was used for data collection.

\section{Statistical Analyses}

The study was conducted using a split plot design where the whole plot factor was fat content and the subplot factor was pasteurization treatment (HTST, IND-UP, or DSI-UP). To determine the effect of thermal treatment on proximate analysis, instrumental color, and SP denaturation results, data were analyzed using the GLM procedure in SAS in SAS 9.4 (SAS Institute, Cary, NC) with thermal treatment, milk fat level, and replicate as category variables with all the 2 -way interactions of these 3 variables. For the analysis of the furosine data, the same procedure as above was used, but time of storage (i.e., d 1 and 14) and appropriate 2-way interactions were added to the model. Least squares means for pasteurization treatment effects within each fat content across time points were determined using the MIXED procedure in SAS 9.4 (SAS Institute) for microbial, furosine, and trained panel profiles. Proximate analysis, instrumental color, SP denaturation, and consumer acceptance data were analyzed by ANOVA with means separation within each fat content (Fisher's least significant difference) using XLSTAT (Version 2015.5.01, Addinsoft, New York, NY). Just about right scores were evaluated using chisquared tests. All statistical analyses were performed at $P<0.05$ significance.

\section{RESULTS AND DISCUSSION}

Raw milk APC averaged $2.63 \pm 2.26$ and $2.09 \pm 1.98$ $\log \mathrm{cfu} / \mathrm{mL}$ of coliforms for skim and $2 \%$, respectively. All milks had APC $<20 \mathrm{cfu} / \mathrm{mL}$ at $\mathrm{d} 3$; at $\mathrm{d} 7$, all samples had APC $<20 \mathrm{cfu} / \mathrm{mL}$. At d 14, the HTST samples averaged $1.54 \log \mathrm{cfu} / \mathrm{mL}$ and the UP milks remained at $<20 \mathrm{cfu} / \mathrm{mL}$. No coliforms were detected $(<10 \mathrm{cfu} / \mathrm{mL})$ at any time point. Skim milk composition averaged $0.068 \%$ fat, $4.72 \%$ lactose, $3.11 \%$ protein, and $8.95 \%$ solids. Two percent fat milks averaged $1.96 \%$ fat, $4.63 \%$ lactose, $3.06 \%$ protein, and $10.71 \%$ solids. The d(0.9) (maximum diameter at which $90 \%$ of the volume of particles are below) for milk fat particle size was $<1.5 \mu \mathrm{m}$ for all milks (means for $2 \%$ milk, HTST $=1.26, \mathrm{IND}-\mathrm{UP}=1.37$, and DSI-UP $=1.18 \mu \mathrm{m}$ ) were comparable to particle size distribution in 16 commercial fluid milk samples [range of $\mathrm{d}(0.9)$ from 1.19 to $1.81 \mu \mathrm{m}]$ reported by Caplan and Barbano (2013). For HTST processing, the homogenization was before the final heating and holding step, whereas for the UP processes the homogenization was after the final heating 
and holding step after the milk had been cooled to $85^{\circ} \mathrm{C}$ (Figure 1). The time-temperature profile of each of the 3 thermal processes (Figure 2) illustrates the difference in total heat exposure of the milk with the IND-UP having much higher total heat exposure. Heat causes denaturation of milk SP, which can covalently bind to the surface of casein micelles (Jang and Swaisgood, 1990) or to native milk fat globule membrane (Lee and Sherbon, 2002). Lee and Sherbon (2002) reported that heating also decreased free sulfhydryl groups in the MFGM and increased disulfide groups, suggesting that incorporation of $\beta$-LG might be due to association with membrane proteins via disulfide bonds. In contrast, Lee and Sherbon (2002) reported that homogenization caused an adsorption of caseins to the MFGM but no binding of whey proteins to the MFGM without heating, and the viscosity of whole milk was increased when milk was treated with both homogenization and heating. The order of homogenization and thermal process may have an influence on color, viscosity, mouthfeel, and astringency of milk and milk protein-based beverages.

Milk composition was not different between treatments in each fat level $(P>0.05)$, indicating that added water from the direct steam injection system was completely removed. All samples were negative for alkaline phosphatase, indicating complete pasteurization.
We noted effects $(P<0.05)$ of heat treatments, but not fat level, on milk $\mathrm{pH}$. No difference in milk $\mathrm{pH}$ was detected between raw milk and HTST milk, but milk $\mathrm{pH}$ for IND-UP was lower than all other heat treatments whereas milk $\mathrm{pH}$ for DSI-UP was higher than all other heat treatments. Milk pH undergoes reversible changes in $\mathrm{pH}$ with increasing temperature with a milk $\mathrm{pH}$ of about 6.58 at $40^{\circ} \mathrm{C}$ and a $\mathrm{pH}$ of 6.25 at $80^{\circ} \mathrm{C}(\mathrm{Ma}$ and Barbano, 2003), but when milk is held at high temperatures for longer periods of time irreversible changes in milk $\mathrm{pH}$ occur. No reversible decreases in milk $\mathrm{pH}$ occur with increasing level of heat treatment because of isomerization and degradation of lactose to produce various organic acids (Walstra et al., 1999); this may also influence flavor, aroma, and color of milk due to production of Maillard products. Our results indicating lower milk pH for the IND-UP (Table 1) are consistent with this finding. No interaction of effect of fat and heat treatment was detected $(P>0.05)$.

We found effects $(P<0.05)$ of all heat treatments and both fat levels on the L, a, and b Hunter color values (Table 1). Based on the relative proportion of type III sum of square, the fat level had the strongest effect on color parameters (particularly L value), followed by heat treatment. We noted an interaction $(P<0.05)$ of heat treatment by fat level for all 3 color parameters. The change in all color parameters due to heat treat-

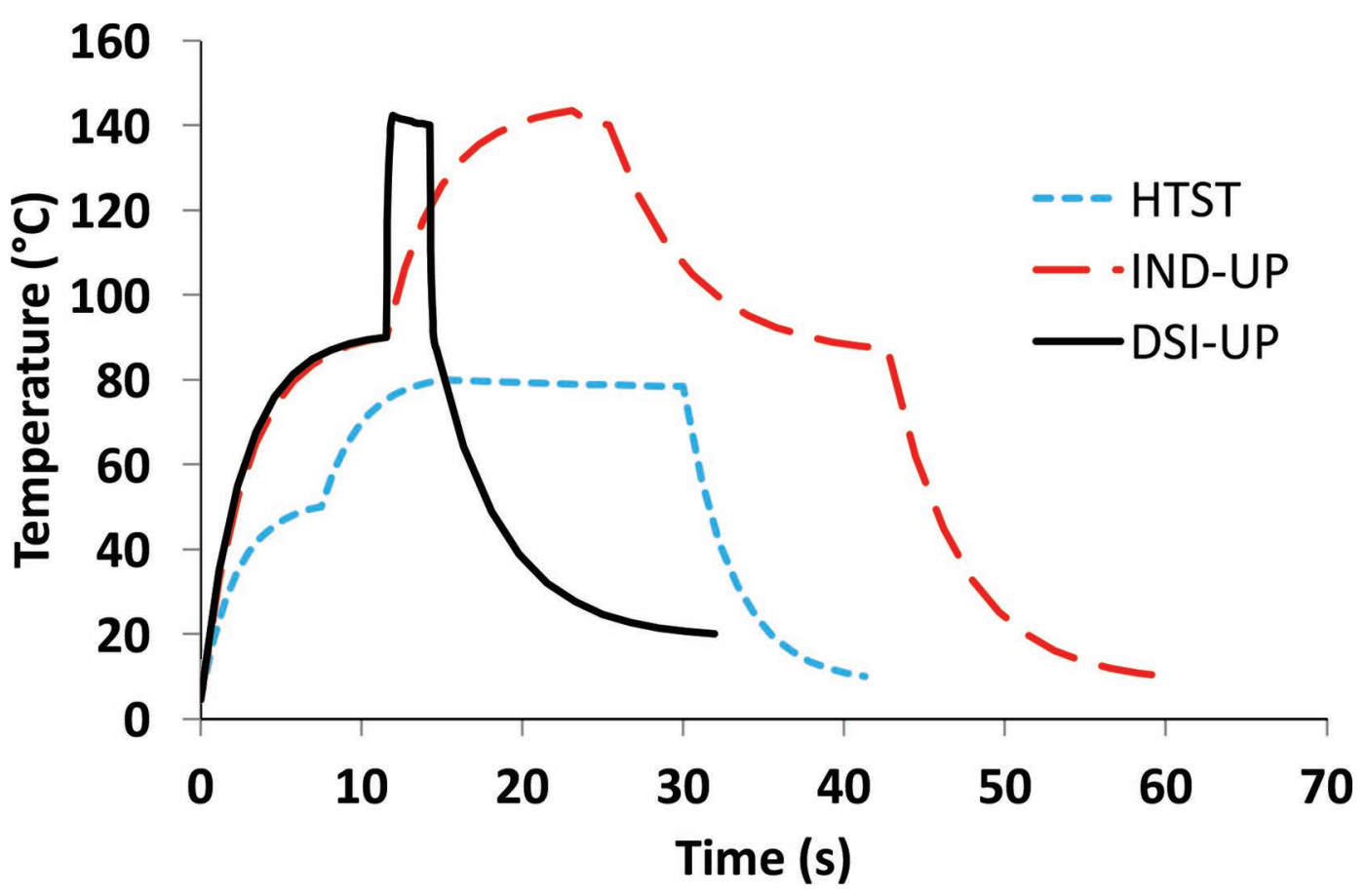

Figure 2. Time-temperature profile of HTST, indirect (IND), and direct steam injection (DSI) ultra-pasteurization (UP) processing for fluid milks under laminar flow assumption. Color version available online. 
Table 1. The effect of different heat treatments, HTST, indirect ultra-pasteurization (IND-UP), and direct steam injection ultra-pasteurization (DIR-UP), on serum protein denaturation (SPDN; \%), milk pH, and Hunter $\mathrm{L}$, a, and $\mathrm{b}$ color values and milk $\mathrm{pH}$ measured at $16.5^{\circ} \mathrm{C}$ for skim and $2 \%$ fat milks at $\mathrm{d} 3$ after processing

\begin{tabular}{|c|c|c|c|c|c|}
\hline \multirow[b]{2}{*}{ Item $^{1}$} & \multirow[b]{2}{*}{ SPDN } & \multirow[b]{2}{*}{$\mathrm{pH}$} & \multicolumn{3}{|c|}{ Hunter color } \\
\hline & & & $\mathrm{L}$ & $\mathrm{a}$ & $\mathrm{b}$ \\
\hline \multicolumn{6}{|c|}{ Heat treatment } \\
\hline Raw & $0^{\mathrm{d}}$ & $6.78^{\mathrm{b}}$ & $76.65^{\mathrm{d}}$ & $-4.80^{\mathrm{d}}$ & $4.02^{\mathrm{d}}$ \\
\hline HTST & $19.97^{\mathrm{c}}$ & $6.78^{\mathrm{b}}$ & $78.74^{\mathrm{c}}$ & $-4.57^{\mathrm{b}}$ & $4.33^{\mathrm{c}}$ \\
\hline IND-UP & $72.56^{\mathrm{a}}$ & $6.73^{\mathrm{c}}$ & $81.29^{\mathrm{a}}$ & $-3.52^{\mathrm{a}}$ & $6.62^{\mathrm{a}}$ \\
\hline DSI-UP & $70.86^{\mathrm{b}}$ & $6.83^{\mathrm{a}}$ & $80.11^{\mathrm{b}}$ & $-4.68^{\mathrm{c}}$ & $4.89^{\mathrm{b}}$ \\
\hline \multicolumn{6}{|l|}{ Fat level } \\
\hline Skim & $38.78^{\mathrm{b}}$ & $6.78^{\mathrm{a}}$ & $76.93^{\mathrm{b}}$ & $-5.45^{\mathrm{b}}$ & $3.75^{\mathrm{b}}$ \\
\hline $2 \%$ fat & $42.92^{\mathrm{a}}$ & $6.78^{\mathrm{a}}$ & $81.47^{\mathrm{a}}$ & $-3.34^{\mathrm{a}}$ & $6.18^{\mathrm{a}}$ \\
\hline
\end{tabular}

ment relative to the raw milk was the largest for the IND-UP. In general, as heat treatment increased the milk became more white, less green, and more yellow.

The $\mathrm{L}$ values were highest for the IND-UP, followed by DSI-UP and the HTST milks. The values for the $2 \%$ milks were higher than those for skim due to the presence of fat. Hunter a-value [redness $(+)$ to greenness $(-)]$ for IND-UP milk was higher (i.e., less green) than DSI-UP and HTST milks $(P<0.05)$, with HTST milks being higher than DSI-UP $(P<0.05)$, but the magnitude of differences were small. Hunter b values [yellowness $(+)$ to blueness $(-)$ ] were significantly different for each milk (IND-UP > DSI-UP > HTST), and $2 \%$ milks were significantly higher than skim $(P<0.05)$. Hunter $\mathrm{a}$ and $\mathrm{b}$ values were higher for $2 \%$ milk than skim milk, as skim milk is more noticeably blue and less yellow, which is a combination of the green and yellow color measured by Hunter a and $b$ values and the lack of the masking effect of the light scattering in skim milk that is caused by milk fat globules in $2 \%$ milk. Hunter L, $\mathrm{a}, \mathrm{b}$ values were lowest for the raw milks $(P<0.05)$. Misawa et al. (2016) reported that the casein percentage of the total protein was strongly correlated with the Hunter L, a, b values. After heat treatment, SP were denatured, decreasing $\mathrm{NCN}$, which in turn increases the casein percentage of the total protein.

Serum protein denaturation was the highest in the IND-UP skim milk (Table 1), which is consistent with the higher total heat exposure (Figure 2) of the milk proteins; thus, it is likely that the $\mathrm{L}$, $\mathrm{a}$, and $\mathrm{b}$ values were affected by SP denaturation, which would be expected to increase casein micelle particle size and increase light scattering that would increase L-value and whiteness. The SP denaturation was not different between the UP $2 \%$ milks, so it is likely that the lack of differences in the $\mathrm{L}$ and a values can also be explained by this. Appear- ance of milk (i.e., the whiteness and opacity) can affect the perception and overall liking of milks by consumers (Quiñones et al., 1997; Palacios et al., 2009; McCarthy et al., 2017). Thus, appearance differences between fat contents and between heat treatments within a fat content can directly influence consumer acceptance; this is consistent with the significant fat by heat treatment interaction $(P<0.05)$ detected in our study, with the difference in color for IND-UP versus DSI-UP on skim $(\mathrm{IND}-\mathrm{UP}=79.6,-4.11$, and 6.28; DSI-UP $=77.53$, -5.82 , and 3.65, HTST $=75.6,-6.02$, and 2.66) and on $2 \%$ milk (IND-UP $=83.0,-2.93$, and 6.96 ; DSI-UP $=82.69,-3.54$, and 6.13 , and HTST 81.9, -3.12, and $6.00)$, respectively, for $\mathrm{L}, \mathrm{a}$, and $\mathrm{b}$ values. The magnitude of whiteness increases in skim milk due to higher heat exposure and results in a larger increase in L-value because the increase in size of casein micelles and the light reflection was not masked by the reflection of light by fat globules. The increase in b-value (yellowness) in the skim was much more apparent than in the $2 \%$ fat milk because of the lack of light scattering due to fat in the skim milk.

\section{Heat Indicators}

We found effects $(P<0.05)$ of all heat treatments and fat level on milk SP denaturation (SPDN; Table 1). The SPDN was higher in $2 \%$ fat milks than in skim for all heat treatments. We noted an interaction $(P$ $<0.05)$ of heat treatment with fat level, with more SPDN observed in the DSI-UP milk at $2 \%$ fat (SPDN $=72.3 \%)$ versus skim milk $(\mathrm{SPDN}=67.9 \%)$ than for IND-UP milk. This may be due to the fact that, in skim milk, SPDN results in SP binding to casein micelles only, whereas in $2 \%$ fat milk the SP binds both to casein micelles and milk fat globule membrane. The 
SPDN was higher for the $2 \%$ fat HTST $($ SPDN $=24 \%)$ milk than for the HTST skim (SPDN $=16 \%)$. Serum protein denaturation would not be expected to change with time of storage.

We found effects $(P<0.05)$ of all heat treatments on furosine concentration in milk (Table 2). The IND-UP milks had the highest average content of furosine, at $168.72 \mathrm{mg} / 100 \mathrm{~g}$ of protein, followed by DSI-UP milks, at $43.81 \mathrm{mg} / 100 \mathrm{~g}$ of protein $(P<0.05)$, and HTST milks, at $6.95 \mathrm{mg} / 100 \mathrm{~g}$ of protein. There was a much larger relative difference furosine levels between IND-UP and DSI-UP than in the difference in SPDN between the 2 thermal treatments. Based on the relative proportion of type III sum of square, the heat treatment had the strongest effect on milk furosine. Milk furosine content increased $(P<0.05)$ with time of storage for both skim and $2 \%$ fat milks, but there was an interaction $(P<$ $0.05)$ of heat treatment with time of storage, with the IND-UP furosine $(\mathrm{d} 1=157.2$, d $14=180.9 \mathrm{mg} / 100 \mathrm{~g}$ of protein) increasing more with time of storage than DSI-UP furosine (d $1=164.5, \mathrm{~d} 14=172.3 \mathrm{mg} / 100 \mathrm{~g}$ of protein) milks. We also noted an interaction of time of storage with milk fat level, with the furosine for the skim IND-UP increasing much more (d $1=157.2, \mathrm{~d}$ $14=180.9 \mathrm{mg} / 100 \mathrm{~g}$ of protein) than the $2 \%$ IND$\mathrm{UP}(\mathrm{d} 1=164.5, \mathrm{~d} 14=172.3 \mathrm{mg} / 100 \mathrm{~g}$ of protein $)$. Thus, one might expect color or flavor defects related to increasing furosine level with time to be apparent earlier in skim than $2 \%$ UP milk. These furosine results are consistent with those found by Elliott et al. (2005).

Both UP treatments received significantly more thermal load than the HTST treatment (Figure 2), as seen in the thermal damage indicators (Tables 1 and 2), with IND-UP being the more severe of the 2 UP treatments. Others have reported that these indicators are dependent on degree, severity, and type of heat treatment (Pellegrino et al., 1995; Cho et al., 2012; Sakkas et al., 2014). Datta et al. (2002) reported that heat indexes (lactulose, furosine, $\beta$-LG, 2-hydroxymethyl-2-furfural) for commercially produced, directly heated UHT milks typically showed less severe heat treatment compared with indirectly heated UHT milks. Elliott et al. (2005) also reported that commercially produced UHT milk samples by direct heating methods had less denatured $\mathrm{SP}$, specifically $\alpha-\mathrm{LA}, \beta-\mathrm{LG}$, and BSA. Storage time did not affect furosine content until after 4 wk of storage at room temperature for UHT milks (Elliott et al., 2005). Others (Cho et al., 2012; Smith et al., 2016) have reported changes in furosine content over time, but low temperature storage retards the increase. The milks were stored at $4^{\circ} \mathrm{C}$ for the duration of our study, so changes in furosine concentration were not expected, but increases $(P<0.05)$ were observed, particularly in skim milk.
Table 2. The effect of different heat treatments, HTST, indirect ultra-pasteurization (IND-UP), and direct steam injection ultrapasteurization (DIR-UP), on furosine concentration $(\mathrm{mg} / 100 \mathrm{~g}$ of protein) for skim and $2 \%$ fat milks at d 1 and 14 after processing

\begin{tabular}{lc}
\hline Item $^{1}$ & $\begin{array}{c}\text { Furosine concentration } \\
(\mathrm{mg} / 100 \mathrm{~g} \text { of protein })\end{array}$ \\
\hline Heat treatment & \\
Raw & $6.95^{\mathrm{c}}$ \\
HTST & $168.72^{\mathrm{a}}$ \\
IND-UP & $43.81^{\mathrm{b}}$ \\
DSI-UP & $72.87^{\mathrm{a}}$ \\
Fat level & $73.46^{\mathrm{a}}$ \\
Skim & $69.72^{\mathrm{b}}$ \\
$2 \%$ & $76.59^{\mathrm{a}}$ \\
Day & \\
1 & \\
14 & ${ }^{\mathrm{a}} \mathrm{c}$ Different letters in columns following means within heat treatment, \\
fat level, or days of storage indicate differences $(P<0.05)$. \\
${ }^{1}$ Standard error of means for heat treatment, fat level, and day of stor- \\
age furosine were $0.965,0.788$, and 0.780, respectively. \\
${ }^{2}$ Furosine concentration not measured for raw milk samples.
\end{tabular}

\section{Descriptive Analysis}

Descriptive analysis was conducted on the milks at 3,7 , and $14 \mathrm{~d}$ postprocessing. Milks were distinguished by heat treatment at all time points $(P<0.05$; Figures 3 and 4 ), and these differences were consistent across skim and $2 \%$ fat milks. The UP milks of either fat content had higher aroma intensity, cooked flavor, and astringency than HTST milk $(P<0.05)$. The UP milks within a fat content were also distinct from each other $(P<0.05)$. The IND milks had higher sweet aromatic flavor and lower sulfur or eggy flavor than DSI milks at $\mathrm{d} 3$ and $7(P<0.05)$. At d 14 , sulfur or eggy flavor was not detected in IND milks of either fat content, but remained at low intensity $(1.0+0.2)$ on a 0 to 15 point scale in DSI milks. Aroma intensity and cooked and sulfur or eggy flavors decreased in UP milks of either fat content across $14 \mathrm{~d}$ of storage $(P<0.05)$, whereas sweet aromatic and cooked flavors decreased across 14 $\mathrm{d}$ of storage for HTST milks $(P<0.05)$.

The sulfur compounds contributing to cooked and sulfur or eggy flavor and aroma in milk have been associated with the denaturation of whey and milk fat globule membrane proteins (Mehta, 1980; Calvo and de la Hoz, 1992). Hydrogen sulfide, dimethyl sulfide, and methanethiol have been suggested as major sulfur containing volatiles contributing to cooked flavor (Blankenagel and Humbert, 1963; Vazquez-Landaverde et al., 2005; Vazquez-Landaverde et al., 2006). The distinct difference in the sensory profile of IND and DSI milks across both fat contents and through $14 \mathrm{~d}$ postprocessing has not been previously reported, but is consistent with the observed increase in furosine (Table 

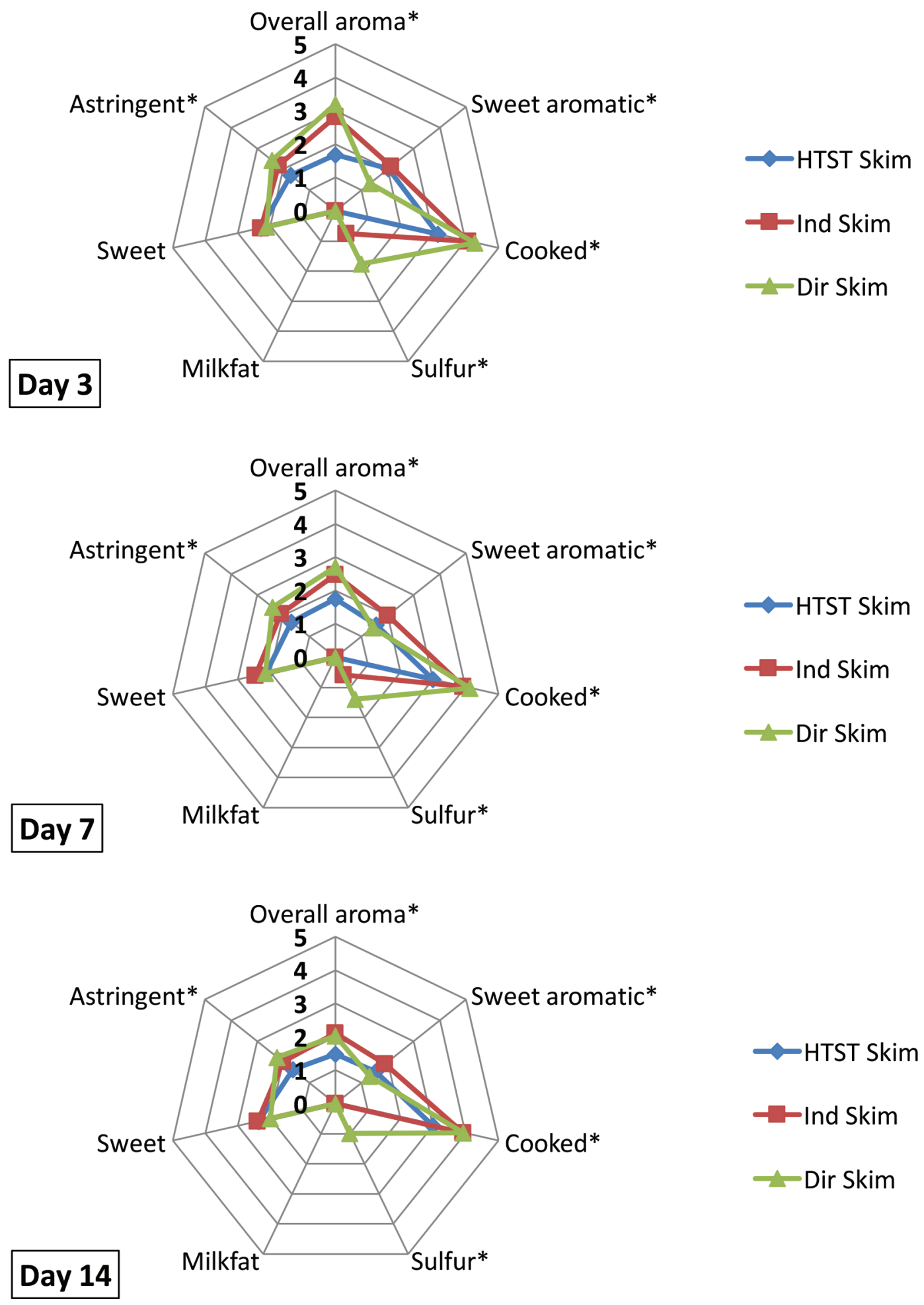

Figure 3. Descriptive analysis results for skim HTST and ultra-pasteurization (UP) milks at d 3, 7, and 14 postprocessing with differences $\left({ }^{*} P<0.05\right)$ for attributes at given time points. Attribute intensities were scored on a 0 to 15 point universal scale. Fluid milk flavors fall between 0 and 4 on this scale (Drake, 2007; Croissant et al., 2007; McCarthy et al., 2016). Standard error of means for attributes was 0.09. Ind = indirect; Dir $=$ direct steam injection. Color version available online. 

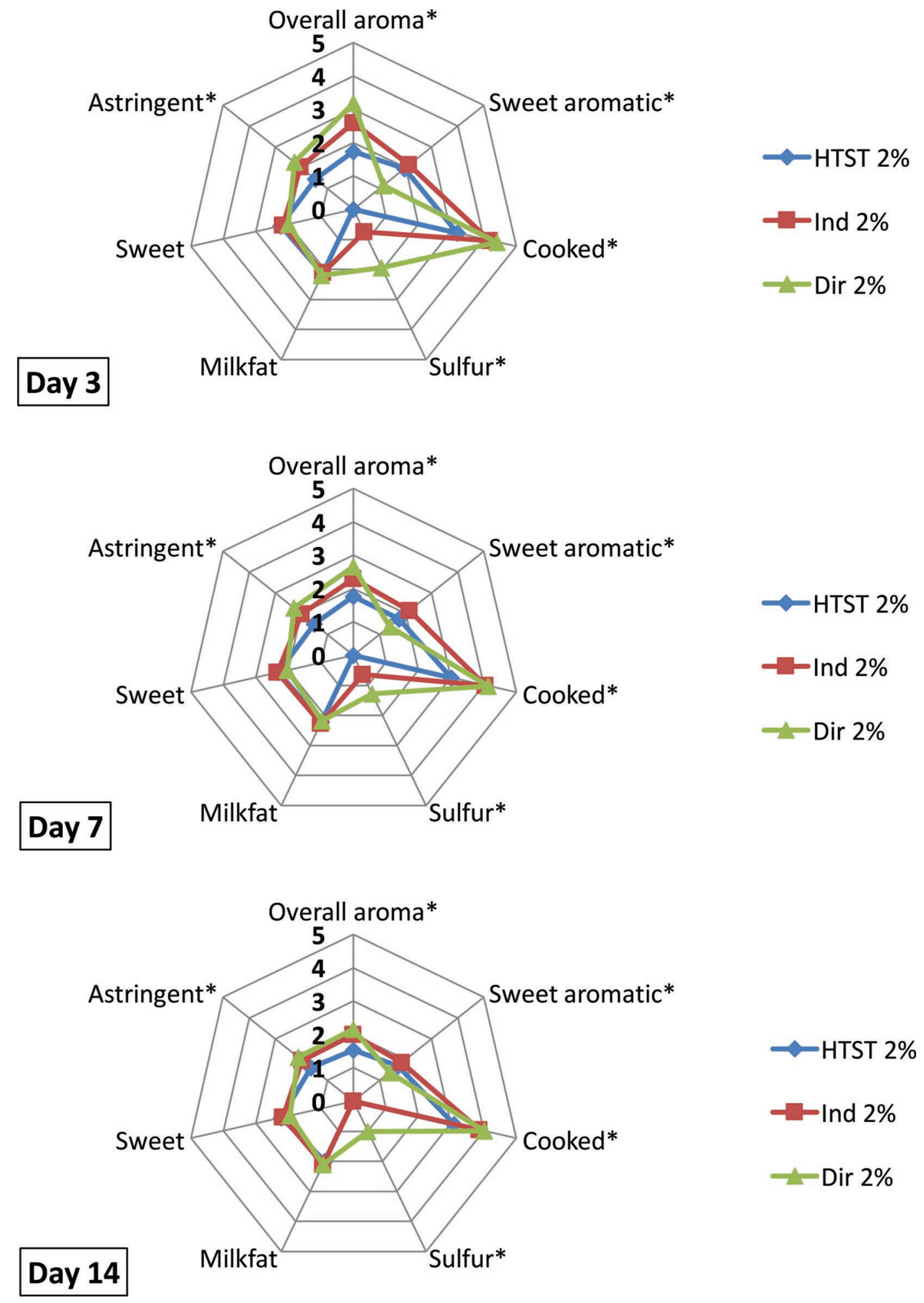

Figure 4. Descriptive analysis results for $2 \%$ milk fat HTST and ultra-pasteurization (UP) milks at d 3, 7 , and 14 postprocessing with differences $\left.{ }^{*} P<0.05\right)$ for attributes at given time points. Attribute intensities were scored on a 0 to 15 point universal scale. Fluid milk flavors fall between 0 and 4 on this scale (Drake, 2007; Croissant et al., 2007; McCarthy et al., 2016). Standard error of means for attributes was 0.09. Ind $=$ indirect; Dir $=$ direct steam injection. Color version available online. 
$2)$. The difference in sulfur or eggy flavor between IND and DSI-UP milks suggests that additional sulfur volatiles are being generated during the DSI-UP process, perhaps due to the temperature difference between the milk and steam. Future studies should characterize volatile compound differences between UP milks from these 2 heating processes and should explore the mechanisms of sulfur volatile compound formation in these processes. The decrease in sweet aromatic and sulfur or eggy flavor and aroma during storage is consistent with previous studies, which examined milk from several days to several months (Shipe et al., 1978; Chapman et al., 2001; Clare et al., 2005), and may be due to oxidation of sulfhydryl groups and lipid oxidation (Thomas et al., 1975) or by diffusion of volatiles through the packaging (Simon and Hansen, 2001; Zabbia et al., 2012). Future studies should address sensory changes beyond $14 \mathrm{~d}$ to account for the 60-d shelf life of UP milks.

Astringency is another attribute of milks that is affected by heat treatment. Whey or SP denatured by heat and aggregated are suggested as one possible mechanism for the astringent mouthfeel of dairy products (Lemieux and Simard, 1994). As previously stated, SPDN was greatest in UP milks. These UP milks had the greatest astringency, suggesting that the heat treatment directly affected this sensory property. Cooked flavors, astringency, and other flavors not commonly associated with typical HTST pasteurized milk may be seen as flavor defects for US consumers (Liem et al., 2016). Palacios et al. (2009) reported that consumers typically preferred light- or medium-impact products when evaluating skim and $2 \%$ milks and milk-substitute beverages. Therefore, focus should be on understanding what compounds are inducing the various sensory attributes of milk as well as how processing conditions can affect their formation.

Trained panelists did not document differences in color or opacity of the milks within a fat content $(P$ $>0.05$; results not shown), but differences $(P<0.05)$ were noted in viscosity between the HTST skim milk and both the IND-UP and DSI-UP skim milks (1.63 vs 1.85 and 1.80 , respectively, on a 0 to 15 point scale) and between the HTST $2 \%$ and IND-UP $2 \%$ milks (1.98 vs 2.20 , respectively, on a 0 to 15 point scale; $P<0.05)$. Chapman et al. (2001) also reported that viscosity of UP skim milks were approximately equal to the viscosity of HTST 1\% fat milks. The differences in viscosity may be attributed to gelation or denaturation of proteins after UP heat treatment. From a consumer standpoint, viscosity can influence perception of fat in the product. McCarthy et al. (2017) reported that consumers typically preferred higher fat content milks than the one they stated they consumed most often. This means that milk that can imitate higher fat content may be more accepted by consumers. Additionally, appearance has been suggested as a more important factor than physical properties, such as viscosity, with regard to fat content perception. With visual cues removed, only $46 \%$ of panelists were able to correctly determine which sample was different between skim and $2 \%$ milks (Phillips et al., 1995). This is consistent with the $4.4 \%$ milk fat threshold with no visual cues reported by McCarthy et al. (2017). Although the trained panel did not note visual differences in milk, previous studies have reported visual differences in the appearance of milks depending on the process used (Datta et al., 2002; Clare et al., 2005). These color changes in fluid milks have been attributed to browning by Maillard reactions. It is possible that differences would be noted between UP and HTST milks if milks were evaluated further into shelf life. Darker-colored milks have been reported to decrease consumer liking of the product (Palacios et al., 2009); thus, color is another consideration for processors when deciding the type of thermal treatment and fat content of fluid milks.

\section{Adult and Child Consumer Acceptance of UP Milks}

Adult skim $(\mathrm{n}=110)$ and $2 \%$ milk fat $(\mathrm{n}=135)$ consumers evaluated the milks after $10 \mathrm{~d}$ of storage. The HTST milks were more liked than either UP treatments for both the skim and $2 \%$ treatments $(P<0.05)$ (Table 3 ). The IND-UP and DSI-UP were at parity for all liking attributes tested $(P>0.05)$; however, consumers indicated that the DSI-UP skim milk was less preferred than the IND-UP skim milk in forced-choice preference (16.4 vs. $28.2 \% ; P<0.05)$. Both UP milks at both fat levels had significant penalties to overall liking due to the milk having "too much flavor," and UP skim milks also received penalties due to having "too thick" mouthfeel $(P<0.05)$. Results from the children's testing revealed similar results (Table 4). Child skim milk $(\mathrm{n}=51)$ and $2 \%$ milk fat $(\mathrm{n}=54)$ consumers also preferred the HTST treatments over either UP treatments for skim and $2 \%$ milks $(P<0.05)$. Aroma liking for DSI-UP $2 \%$ fat milk was significantly lower than for IND-UP $2 \%$ milk $(P<0.05)$, but we found no other differences in liking among the attributes tested between IND-UP and DSI-UP milks at either fat level (results not shown; $P>0.05$ ). In contrast with the adult consumer testing results, UP $2 \%$ milks had significant penalties from children to overall liking due to "too thin" mouthfeel (results not shown; $P<0.05$ ).

As previously mentioned, US milk consumers typically prefer light or medium milk flavor intensity (Palacios et al., 2009). Our study agrees with these findings; the UP milks were consistently penalized by adult consumers for having "too much flavor." Based on trained panel 
Table 3. Adult consumer acceptance results for skim and $2 \%$ milks treated by HTST pasteurization or UP

\begin{tabular}{|c|c|c|c|c|c|c|}
\hline Treatment & \multicolumn{3}{|c|}{ Skim milk ${ }^{2}($ consumers $\mathrm{n}=110)$} & \multicolumn{3}{|c|}{$2 \%$ fat milk $^{3}($ consumers $\mathrm{n}=135)$} \\
\hline HTST & $7.0^{\mathrm{a}}$ & $6.9^{\mathrm{a}}$ & $55.5 \%^{\mathrm{a}}$ & $7.1^{\mathrm{a}}$ & $7.1^{\mathrm{a}}$ & $51.1 \%^{\mathrm{a}}$ \\
\hline DSI-UP & $6.0^{\mathrm{b}}$ & $5.8^{\mathrm{b}}$ & $16.4 \%^{\mathrm{c}}$ & $6.3^{\mathrm{b}}$ & $6.2^{\mathrm{b}}$ & $27.4 \%^{\mathrm{b}}$ \\
\hline
\end{tabular}

${ }^{\mathrm{a}-\mathrm{c}}$ Different letters in columns following means within each fat level indicate differences $(P<0.05)$.

${ }^{1}$ Liking attributes were scored on a 9-point hedonic scale where $1=$ dislike extremely and $9=$ like extremely.

${ }^{2}$ Standard error of means for overall liking and flavor liking were 0.18 and 0.19 , respectively.

${ }^{3}$ Standard error of means for overall liking and flavor liking were 0.16 and 0.16 , respectively.

profiles, high cooked flavor and sulfur or eggy flavor are the flavors that are not liked by consumers. Gandy et al. (2008) also reported that some consumer clusters could be distinguished by bias toward or against cooked flavor in milk. This bias can be dependent on the type of milk most commonly consumed. Liem et al. (2016) reported that consumers from China, where $60 \%$ of the milk consumed is UHT milk, preferred the flavor of UHT milk, whereas consumers from Australia, where only $10 \%$ of milk consumed is UHT, preferred HTST milk. Chapman and Boor (2001) reported that children 6 to 11 yr preferred HTST milk over UP and UHT milks, likely due to the cooked flavor differences compared with traditional HTST milks. Trained panelists documented distinct differences in the nature of the cooked flavor of the UP milks processed by IND or DSI, although consumers did not have differences in liking for these milks. As such, we can conclude that high cooked flavor intensity in general, with or without higher sulfur or eggy flavor, is not preferred by consumers compared with traditional HTST milks. The preheat temperature for UP of milk is high $\left(80-90^{\circ} \mathrm{C}\right)$ and, regardless of if the milk is processed by DSI or IND, a significant effect on cooked flavor is the result. With the increase in UP technology and greater access and exposure to UP milks, we had hypothesized differences in liking of the specific flavor profile of IND versus DSI milk or differences in consumer acceptance of UP pro- cessed milks since the last limited study more than 10 yr ago (Chapman and Boor, 2001). These results do not support this hypothesis and demonstrate the direct effect of heat treatment on consumer acceptance of milks. With the increased use of DSI over IND, future studies should investigate the volatile compound differences between DSI and IND to further elucidate possibilities to mitigate cooked flavors.

\section{CONCLUSIONS}

Heat treatment affects sensory properties and consumer acceptance of milk. Trained panelists were able to distinguish between the HTST and UP milks based on cooked flavor. Presence of sulfur or eggy flavor and aroma distinguished DSI-UP from IND-UP milk. Flavor intensities decreased with storage time, but HTST, IND-UP, and DSI-UP milks remained distinct at d 14 for both fat contents. The UP milks exhibited greater thermal treatment by furosine and SP denaturation than the HTST milks. Color differences were also present by instrumental analysis at d 3, but the trained panel did not detect visual differences at any time point through d 14. Adult and child milk consumers had a significant preference for HTST milk over either UP milk for skim and $2 \%$ fat milks, with no differences in liking between the UP milks at either fat content; however, IND-UP skim was preferred over DSI-UP skim by

Table 4. Child consumer acceptance results for skim and $2 \%$ milks treated by HTST pasteurization or UP

\begin{tabular}{|c|c|c|c|c|c|c|}
\hline Treatment & \multicolumn{3}{|c|}{ Skim milk $^{2}($ consumers $n=51)$} & \multicolumn{3}{|c|}{$2 \%$ fat milk $^{3}($ consumers $\mathrm{n}=54)$} \\
\hline HTST & $5.5^{\mathrm{a}}$ & $5.4^{\mathrm{a}}$ & $58.8 \%^{\mathrm{a}}$ & $5.6^{\mathrm{a}}$ & $5.6^{\mathrm{a}}$ & $63.0 \%^{\mathrm{a}}$ \\
\hline DSI-UP & $4.4^{\mathrm{b}}$ & $4.3^{\mathrm{b}}$ & $15.7 \%^{\mathrm{b}}$ & $4.5^{\mathrm{b}}$ & $4.4^{\mathrm{b}}$ & $16.7 \%^{\mathrm{b}}$ \\
\hline
\end{tabular}


adults. Consumers have preferences for certain sensory characteristics of milk that are influenced by both heat treatment and fat content. Thus, processors must take the effects of these parameters into account when producing fluid milk to meet consumer expectations and to maximize acceptance.

\section{ACKNOWLEDGMENTS}

This project was supported in part by the National Dairy Council (Rosemont, IL).

\section{REFERENCES}

AOAC International. 2012. Official Methods of Analysis. 19th ed. AOAC International, Gaithersburg, MD.

Barbano, D. M., and J. L. Clark. 1990. Kjeldahl method for determination of total nitrogen content of milk: Collaborative study. J. Assoc. Off. Anal. Chem. 73:849-859.

Barbano, D. M., and J. M. Lynch. 1991. Direct and indirect determination of true protein content of milk by Kjeldahl analysis: Collaborative study. J. Assoc. Off. Anal. Chem. 74:281-288.

Blankenagel, G., and E. S. Humbert. 1963. Sulfhydryl groups and cooked flavor in ultra-high temperature processed skim milk. J. Dairy Sci. 46:614.

Boor, K. J. 2001. Fluid dairy product quality and safety: Looking to the future. J. Dairy Sci. 84:1-11.

Bylund, G. 2003. Long life milk, Chapter 9. Pages 215-232 in: Dairy processing handbook. Lund, Sweden. Tetra Pak Processing Systems $\mathrm{AB}$

Calvo, M. M., and L. de la Hoz. 1992. Flavour of heated milks. A Review. Int. Dairy J. 2:69-81.

Caplan, Z., and D. M. Barbano. 2013. Shelf life of pasteurized microfiltered milk containing $2 \%$ fat. J. Dairy Sci. 96:8035-8046.

Chapman, K. W., and K. J. Boor. 2001. Acceptance of $2 \%$ ultrapasteurized milk by consumers, 6 to 11 years old. J. Dairy Sci. 84:951-954.

Chapman, K. W., H. T. Lawless, and K. J. Boor. 2001. Quantitative descriptive analysis and principal component analysis for sensory characterization of ultra-pasteurized milk. J. Dairy Sci. 84:12-20.

Cho, Y. H., S. M. Hong, and C. H. Kim. 2012. Determination of lactulose and furosine formation in heated milk as a milk quality indicator. Korean J. Food. Sci. An. 32:540-544.

Clare, D. A., W. S. Bang, G. Cartwright, M. A. Drake, P. Coronel, and J. Simunovic. 2005. Comparison of sensory, microbiological, and biochemical parameters of microwave versus indirect UHT fluid milk skim milk during storage. J. Dairy Sci. 88:4172-4182.

Croissant, A. E., S. P. Washburn, L. L. Dean, and M. A. Drake. 2007. Chemical properties and consumer perception of fluid milk from conventional and pasture-based production systems. J. Dairy Sci. 90:4942-4953.

Datta, N., A. J. Elliott, M. L. Perkins, and H. C. Deeth. 2002. Ultrahigh-temperature UHT treatment of milk: Comparison of direct and indirect modes of heating. Aust. J. Dairy Technol. 57:211-227.

Deane, D. D., J. A. Chelesvig, and W. R. Thomas. 1967. Pasteurization treatment and consumer acceptance of milk. J. Dairy Sci. 50:1216-1220

DiMarzo, L., P. Cree, and D. M. Barbano. 2016. Prediction of fat globule particle size in homogenized milk using Fourier transform mid-infrared. J. Dairy Sci. 99:8549-8560.

Drake, M. A. 2007. Invited review: Sensory analysis of dairy foods. J. Dairy Sci. 90:4925-4937.

Elliott, A. J., N. Datta, B. Amenu, and H. C. Deeth. 2005. Heatinduced and other chemical changes in commercial UHT milks. J. Dairy Res. 72:442-446.
FDA. 2015. 21 CFR 131.3. Accessed May 9, 2016. http://www accessdata.fda.gov/scripts/cdrh/cfdocs/cfcfr/CFRSearch. $\mathrm{cfm} ? \mathrm{fr}=131.3$.

Gandy, A. L., M. W. Schilling, P. C. Coggins, C. H. White, Y. Yoon, and V. V. Kamadia. 2008. The effect of pasteurization temperature on consumer acceptability, sensory characteristics, volatile compound composition, and shelf-life of fluid milk. J. Dairy Sci. 91:1769-1777.

Graobowski, N. T., B. Ahlfeld, A. Brix, A. Hagemann, C. von Munchhausen, and G. Klein. 2013. Similarities and differences among fluid milk products: Traditionally produced, extended shelf life and ultrahigh-temperature processed. Food Sci. Technol. Int. 19:235-241.

Jang, H. D., and H. E. Swaisgood. 1990. Disulfide bond formation between thermally denatured $\beta$-lactoglobulin and $\kappa$-casein in casein micelles. J. Dairy Sci. 73:900-904.

Jelen, P. 1982. Experience with direct and indirect UHT processing of milk-A Canadian viewpoint. J. Food Prot. 45:878-883.

Kaylegian, K. E., G. E. Houghton, J. M. Lynch, J. R. Fleming, and D. M. Barbano. 2006. Calibration of infrared milk analyzers: Modified milk versus producer milk. J. Dairy Sci. 89:2817-2832.

Lee, S. J., and J. W. Sherbon. 2002. Chemical changes in bovine milk fat globule membrane caused by heat treatment and homogenization of whole milk. J. Dairy Res. 69:555-567.

Lemieux, L., and R. E. Simard. 1994. Astringency, a textural defect in dairy products. Lait 74:217-240.

Li, X. E., K. Lopetcharat, Y. Qiu, and M. A. Drake. 2015. Sugar reduction of skim chocolate milk and viability of alternative sweetening through lactose hydrolysis. J. Dairy Sci. 98:1455-1466.

Liem, D. G., D. P. Bolhuis, X. Hu, and R. S. J. Keast. 2016. Short communication: Influence of labeling on Australian and Chinese consumers' liking of milk with short (pasteurized) and long (UHT) shelf life. J. Dairy Sci. 99:1747-1754.

Lynch, J. M., and D. M. Barbano. 1998. Indirect and direct determination of the casein content of milk by Kjeldahl nitrogen analysis: Collaborative study. J. AOAC Int. 81:763-774.

Lynch, J. M., D. M. Barbano, M. Schweisthal, and J. R. Fleming. 2006. Precalibration evaluation procedures for mid-infrared milk analyzers. J. Dairy Sci. 89:2761-2774.

Ma, Y., and D. M. Barbano. 2003. Milk pH as a function of $\mathrm{CO}_{2}$ concentration, temperature, and pressure in a heat exchanger. J. Dairy Sci. 86:3822-3830.

McCarthy, K. S., K. Lopetcharat, and M. A. Drake. 2017. Milkfat threshold determination and the effect of milkfat content on consumer preference of fluid milk. J. Dairy Sci. https://doi org/10.3167/jds.2016-11417.

Mehta, R. S. 1980. Milk processed at ultra-high-temperatures-A review. J. Food Prot. 43:212-225.

Meilgaard, M. C., G. V. Civille, and B. T. Carr. 2007. Descriptive analysis techniques, Chapter 10. Pages 173-186 in Sensory Evaluation Techniques, 4th ed. CRC Press, Boca Raton, FL.

Misawa, N., D. M. Barbano, and M. A. Drake. 2016. Influence of casein as a percentage of true protein and protein level on color and texture of milks containing 1 and $2 \%$ fat. J. Dairy Sci. 99:5284-5304.

Palacios, O. M., J. Bardran, M. A. Drake, M. Reisner, and H. R. Moskowitz. 2009. Consumer acceptance of cow's milk versus soy beverages: Impact of ethnicity, lactose tolerance and sensory preference segmentation. J. Sens. Stud. 24:731-748.

Pellegrino, L., I. De Noni, and P. Resmini. 1995. Coupling of lactulose and furosine indices for quality evaluation of sterilized milk. Int Dairy J. 5:647-659.

Phillips, L. G., M. L. McGiff, D. M. Barbano, and H. T. Lawless. 1995. The influence of fat on the sensory properties, viscosity, and color of lowfat milk. J. Dairy Sci. 78:1258-1266.

Quiñones, H. J., D. M. Barbano, and L. G. Phillips. 1997. Influence of protein standardization by ultrafiltration on the viscosity, color, and sensory properties of skim and $1 \%$ milk. J. Dairy Sci 80:3142-3151.

Quiñones, H. J., D. M. Barbano, and L. G. Phillips. 1998. Influence of protein standardization by ultrafiltration on the viscosity, color 
and sensory properties of 2 and 3.3\% milks. J. Dairy Sci. 81:884894.

Rauh, V. M., L. B. Johansen, M. Bakman, R. Ipsen, M. Paulsson, L. B. Larsen, and M. Hammershoj. 2015. Protein lactosylation in UHT milk during storage measured by liquid chromatographymass spectrometry and quanitification of furosine. Int. J. Dairy Technol. 68:486-494.

Resmini, P., L. Pellegrino, and G. Batteli. 1990. Accurate quantification of furosine in milk and dairy products by a direct HPLC method. Ital. J. Food Sci. 2:173-183.

Sakkas, L., A. Moutafi, E. Moschopoulou, and G. Moatsou. 2014. Assessment of heat treatment of various types of milk. Food Chem. 159:293-301.

Shipe, W. F., R. Bassette, D. D. Deane, W. L. Dunkley, E. G. Hammond, W. J. Harper, D. H. Kleyn, M. E. Morgan, J. H. Nelson, and R. A. Scanlan. 1978. Off flavors of milk: Nomenclature, standards, and bibliography. J. Dairy Sci. 61:855-869.

Simon, M., and A. P. Hansen. 2001. Effect of various dairy packaging materials on the shelf life and flavor of ultra-pasteurized milk. J. Dairy Sci. 84:784-791.

Smith, T. J., R. E. Campbell, Y. Jo, and M. A. Drake. 2016. Flavor and stability of milk proteins. J. Dairy Sci. 99:4325-4346.
Thomas, E. L., H. Burton, J. E. Ford, and A. G. Perkin. 1975. The effect of oxygen content on flavor and chemical changes during asceptic storage of whole milk after ultra-high-temperature processing. J. Dairy Res. 42:285-295.

USDA ERS. 2015. Food Availability Per Capita Data System. USDA, Economic Research Service. Accessed Aug. 20, 2015. http://www. ers.usda.gov/data-products/dairy-data.aspx.

Vazquez-Landaverde, P. A., J. A. Torres, and M. C. Qian. 2006. Quantification of trace volatile sulfur compounds in milk by solid-phase microextraction and gas chromatography-pulsed flame photometric detection. J. Dairy Sci. 89:2919-2927.

Vazquez-Landaverde, P. A., G. Velazquez, J. A. Torres, and M. C. Qian. 2005. Quantitative determination of thermally derived offflavor compounds in milk using solid-phase microextraction and gas chromatography. J. Dairy Sci. 88:3764-3772.

Walstra, P., T. J. Geurts, A. Noomen, A. Jellerma, and M. A. J. S. van Boekel. 1999. Dairy Technology: Principles of Milk Properties and Processes. Marcel Dekker Inc., New York.

Zabbia, A., E. M. Buys, and H. L. de Kock. 2012. Undesirable sulfur and carbonyl flavor compounds in UHT milk: A review. Crit. Rev. Food Sci. Nutr. 52:21-30. 